\title{
DINÂMICA PRÉ E PÓS-COLOSTRAL DE PARÂMETROS BIOQUÍMICOS EM CORDEIROS
}

\author{
DAMARIS FerReira de SOUZA ${ }^{1}$, Alda LÚCia GOMES MONTEIRO², ROSANGela LOCATElli \\ DitTrich ${ }^{2}$, ElizABETH MOREIRA DOS SANTOS SCHMIDT ${ }^{3}$, SERGIO ROdRIGO FERNANDES ${ }^{2}$, OlaIR \\ CARLOS BELTRAME ${ }^{4}$ \\ ${ }^{1}$ Pós-Graduanda da Universidade Federal do Paraná, Curitiba, PR, Brasil - fs.damaris@ gmail.com \\ ${ }^{2}$ Docentes Doutores da Universidade Federal do Paraná, Curitiba, PR, Brasil \\ ${ }^{3}$ Professora Doutora da Universidade Estadual Paulista Júlio de Mesquita Filho, Botucatu, SP, Brasil \\ ${ }^{4}$ Bioquímico, Laboratório de Patologia Clinica Veterinária, Universidade Federal do Paraná, Curitiba, PR, Brasil
}

\section{RESUMO}

O objetivo deste estudo foi verificar a influência do colostro nos parâmetros bioquímicos séricos em cordeiros recém-nascidos. Foram colhidas amostras sanguíneas de 28 cordeiros, determinando-se os indicadores proteicos, energéticos, de função renal, bilirrubinas e as enzimas aspartato aminotransferase (AST), gamaglutamiltransferase (GGT) e creatina quinase (CK), nos momentos pré e pós-colostro. Os dados foram analisados comparando-se a variabilidade dos parâmetros entre os dois momentos. Houve elevação $(P<0,001)$ das concentrações de proteínas totais, em resposta ao forte aumento $(P<0,01)$ dos teores de globulinas totais e ao leve decréscimo $(P<0,05)$ da concentração de albumina, após a ingestão colostral. Também foram observados maiores valores de bilirrubinas total e direta $(P<0,001)$, e variação dos metabólitos renais, com elevação dos níveis de ureia $(P<0,01)$ concomitante à redução dos valores de creatinina $(P<0,001)$, no momento pós-colostro. Houve aumento $(P<0,001)$ da glicemia, de colesterol total e triglicerídeos, bem como das atividades enzimáticas $(P<0,001)$ de AST e GGT, entre os momentos avaliados. Conclui-se que a dinâmica do perfil bioquímico em cordeiros recémnascidos sofre o efeito da ingestão de colostro e da adaptação das funções fisiológicas à vida extra-uterina. Os valores dos parâmetros variam marcadamente no período pós-natal, sendo recomendável a utilização de valores de referência próprios para esta fase.

PALAVRAS-CHAVE: amamentação, bioquímica clínica, neonato, ovino, sangue.

\section{PRE AND POST-COLOSTRAL DYNAMICS OF BIOCHEMICAL PARAMETERS IN LAMBS}

\section{ABSTRACT}

This study aimed to verify the influence of colostrum in serum biochemical parameters in newborn lambs. Blood samples were taken of 28 lambs, determining the protein, energy and kidney function indicators, bilirrubins and the enzymes aspartate aminotransferase (AST), gammaglutamyl transferase (GGT) and creatine kinase (CK), in pre and post-colostrum moments. The data were analyzed comparing the variability of the parameters between the two moments. There was an elevation $(P<0.001)$ in total protein concentrations, in response to substantial increase $(P<0.01)$ in total globulin levels, and a slight decrease $(P<0.05)$ in albumin concentration, after colostral intake. We also observed higher values of total and conjugated bilirubins $(P<0.001)$, and variation of kidney metabolites, with an elevation of urea levels $(P<0.01)$ concomitant to decrease of creatinine values $(P<0.001)$ in the postcolostrum moment. There was an increase $(P<0.001)$ in glycemia, total cholesterol and triglycerides, as well as of 
the enzymatic activities $(P<0.001)$ of AST and GGT, between the moments evaluated. In conclusion, the dynamics of biochemical profile in newborn lambs suffers the effect of colostrum intake and of adaptations of physiological functions to extrauterine life. The parameters values vary markedly in the postnatal period, being recommended to use proper reference values for this phase.

KEYWORDS: blood, clinical biochemistry, neonate, nursing, sheep.

\section{INTRODUÇÃO}

A fase neonatal caracteriza-se como período crucial no desenvolvimento dos sistemas corporais de um indivíduo. Os recém-nascidos tornam-se responsáveis pela sua própria manutenção homeostática, anteriormente realizada pela placenta, e intensas modificações fisiológicas devem garantir sua sobrevivência no ambiente extra-uterino ${ }^{1,2}$.

O nascimento é um momento muito estressante para o neonato e, somado à instabilidade metabólica, desencadeia maior vulnerabilidade às doenças perinatais. Nessa fase, registram-se elevadas taxas de mortalidade, que repercutem em vultosos prejuízos econômicos aos sistema de produção ${ }^{3,4}$.

Os pequenos ruminantes possuem placentação do tipo sindesmocorial, cujo maior número de estratos tissulares separando a circulação materna da fetal impossibilita a adequada transferência de anticorpos da mãe para o feto. Dessa forma, os recém-nascidos destas espécies nascem hipo ou agamaglobulinêmicos e sua sobrevivência depende diretamente do consumo de colostro nas primeiras horas de vida ${ }^{5}$ ${ }^{8}$. O colostro encontra-se intimamente vinculado aos mecanismos de defesa imunológica e ao aporte de nutrientes para os neonatos, interferindo marcadamente sobre muitas características sanguíneas que serão modificadas com o progresso da idade ${ }^{9-11}$.

$\mathrm{Na}$ espécie ovina, informações sobre a cinética dos parâmetros sanguíneos em animais sadios são escassas, sobretudo em animais jovens. Além disso, uma parcela dos trabalhos produzidos não é disponibilizada facilmente ou está relacionada a condições estritamente particulares de uma região ${ }^{12-20}$. Ainda não há uma compreensão clara de como o colostro e outros fatores alteram o comportamento dos constituintes sanguíneos na fase neonatal.

São raros os trabalhos que remetem à determinação de valores de referência do perfil bioquímico em cordeiros recém-nascidos, dentre os quais se destacam, na literatura nacional, aqueles relacionados à avaliação da transferência de imunidade passiva ${ }^{21-27}$.

Assim, o objetivo deste estudo foi verificar a influência da ingestão de colostro sobre os parâmetros bioquímicos séricos (indicadores proteicos, energéticos, de função renal, bilirrubinas e enzimas) em cordeiros recémnascidos sadios, fornecendo subsídios que contribuam para a interpretação de exames laboratoriais durante o período neonatal.

\section{MATERIAL E MÉTODOS}

O protocolo experimental (016/2011 de 04 de agosto de 2011) foi aprovado pela Comissão de Ética no Uso de Animais do Setor de Ciências Agrárias, da Universidade Federal do Paraná, Brasil.

O estudo foi conduzido no Laboratório de Produção e Pesquisa em Ovinos e Caprinos (LAPOC), da Universidade Federal do Paraná

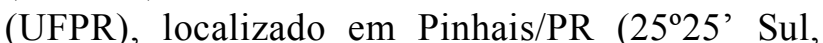
$49^{\circ} 8^{\prime}$ Oeste e $930 \mathrm{~m}$ de altitude). Foram colhidas amostras de sangue de 28 cordeiros sadios (13 mestiços $1 / 2$ Suffolk x $1 / 2$ White Dorper, nascidos entre setembro e outubro de 2010 - primavera; e 15 Suffolk PO, nascidos em agosto de 2011 - final do inverno), sendo 21 fêmeas e sete machos. Os animais foram avaliados em dois momentos: pré e pós-colostro.

As amostras sanguíneas do momento précolostro foram obtidas logo após o nascimento, antes da primeira mamada. As amostras póscolostrais foram obtidas às 72 horas de vida, após certificação da ingestão de colostro durante a primeira hora após o nascimento. Nesse período, os cordeiros permaneceram com suas respectivas mães e foram realizados os procedimentos de desinfecção umbilical (com iodo a 10\%, uma vez ao dia) e de identificação com brincos. Nenhuma complicação foi observada após essas intervenções.

Em ambos os momentos, foram colhidas amostras de $2 \mathrm{~mL}$ de sangue por meio de venopunção jugular dos cordeiros. As amostras foram transferidas para tubos sem anticoagulante, mantidas em repouso até formação do coágulo, e em seguida foram centrifugadas a 4.000 RPM por 
10 minutos. O soro obtido foi armazenado a -20 ${ }^{\circ} \mathrm{C}$ até o processamento das análises. Todos os exames foram realizados no Laboratório de Patologia Clínica Veterinária da UFPR.

As amostras de soro foram processadas em analisador bioquímico automatizado (BS-200, Myndray $\left.{ }^{\circledR}\right)$. Determinaram-se os seguintes parâmetros: proteínas totais (método do biureto, Katal®), albumina (método do verde de bromocresol, Katal®), globulinas totais (pela diferença entre proteínas totais e albumina), bilirrubina total e direta (método de Jendrassik Grof, Dialab®), bilirrubina indireta (pela diferença entre bilirrubina total e direta), ureia (método UV enzimático da urease-GLDH, Kovalent $\left.{ }^{\circledR}\right)$, creatinina (método de Jaffé, Kovalent ${ }^{\circledR}$ ), colesterol total (método enzimático do CHODPAP, Kovalent ${ }^{\circledR}$ ), triglicerídeos (método enzimático do GPO-PAP, Kovalent ${ }^{\circledR}$ ), glicose (método enzimático da glicose, Katal®), e as enzimas aspartato aminotransferase (método cinético UV da AST, Katal®), creatina quinase (método cinético UV da CK, Katal®) e gamaglutamiltransferase (método cinético da GGT, Katal®).

Os dados obtidos foram submetidos ao teste de normalidade de Shapiro-Wilk $(P=0,05)$. Os parâmetros que apresentaram resíduos com distribuição normal foram submetidos à análise de variância (ANOVA) e as médias comparadas pelo teste $\mathrm{t}$ de Student $(P=0,05)$. Os parâmetros que não atenderam à condição de normalidade dos resíduos foram submetidos ao teste não-paramétrico de Kruskal Wallis $(P=0,05)$. A análise estatística foi realizada utilizando-se o programa $R$ Project for Statistical Computing, versão 2.10.1 (28).

\section{RESULTADOS E DISCUSSÃO}

As médias e erros-padrão dos parâmetros avaliados encontram-se na Tabela 1.

Tabela 1. Médias e erros-padrão $(\mathrm{M} \pm \mathrm{EP})$ de parâmetros bioquímicos séricos em cordeiros recém-nascidos, antes e após a ingestão de colostro

\begin{tabular}{lccc}
\hline Parâmetros & Pré-colostro & Pós-colostro & $P$ \\
\hline${ }^{1}$ Proteínas Totais $(\mathrm{g} / \mathrm{L})$ & $41,9 \pm 0,7$ & $64,9 \pm 2,2$ & $* * *$ \\
${ }^{1}$ Albumina $(\mathrm{g} / \mathrm{L})$ & $31,6 \pm 0,2$ & $29,7 \pm 0,4$ & $*$ \\
${ }^{1}$ Globulinas Totais $(\mathrm{g} / \mathrm{L})$ & $10,3 \pm 0,6$ & $35,2 \pm 2,0$ & $* * *$ \\
${ }^{1}$ Ureia $(\mathrm{mmol} / \mathrm{L})$ & $7,2 \pm 0,4$ & $10,5 \pm 0,7$ & $* *$ \\
${ }^{1}$ Creatinina $(\mu \mathrm{mol} / \mathrm{L})$ & $222,5 \pm 23,9$ & $55,5 \pm 3,1$ & $* * *$ \\
${ }^{1}$ Bilirrubina Total $(\mu \mathrm{mol} / \mathrm{L})$ & $11,8 \pm 1,3$ & $24,2 \pm 2,8$ & $* * *$ \\
${ }^{1}$ Bilirrubina Direta $(\mu \mathrm{mol} / \mathrm{L})$ & $3,9 \pm 0,4$ & $17,5 \pm 2,6$ & $* * *$ \\
${ }^{1}$ Bilirrubina Indireta $(\mu \mathrm{mol} / \mathrm{L})$ & $7,9 \pm 0,9$ & $6,7 \pm 1,2$ & $\mathrm{NS}$ \\
${ }^{1}$ Glicose $(\mathrm{mmol} / \mathrm{L})$ & $3,59 \pm 0,78$ & $6,73 \pm 0,40$ & $* * *$ \\
${ }^{2}$ Colesterol Total $(\mathrm{mmol} / \mathrm{L})$ & $0,32 \pm 0,04$ & $2,21 \pm 0,12$ & $* * *$ \\
${ }^{1}$ Triglicerídeos $(\mathrm{mmol} / \mathrm{L})$ & $0,43 \pm 0,05$ & $1,32 \pm 0,20$ & $* * *$ \\
${ }^{1}$ AST $(\mathrm{U} / \mathrm{L})$ & $20,3 \pm 1,0$ & $63,7 \pm 3,1$ & $* * *$ \\
${ }^{1}$ GGT $(\mathrm{U} / \mathrm{L})$ & $55,1 \pm 2,9$ & $877,0 \pm 155,3$ & $* * *$ \\
${ }^{1} \mathrm{CK}(\mathrm{U} / \mathrm{L})$ & $183,3 \pm 25,0$ & $179,7 \pm 27,7$ & $\mathrm{NS}$ \\
\hline
\end{tabular}

Parâmetros: AST = aspartato aminotransferase; GGT = gama-glutamiltransferase; $\mathrm{CK}=$ creatina quinase

${ }^{1}$ Médias comparadas pelo teste de Kruskal Wallis.

${ }^{2}$ Média comparada pelo teste $\mathrm{t}$ de Student.

$*$, **, ***, indicam $P \leq 0,05 ; P \leq 0,01$ e $P \leq 0,001$; respectivamente.

$\mathrm{NS}=$ ausência de diferença estatística significativa entre as médias $(P>0,05)$.

As concentrações de proteínas totais dos cordeiros variaram paralelamente com as concentrações de globulinas totais. No momento pré-colostro, ambos os parâmetros apresentaram-se em teores muito baixos e se elevaram $(P<0,001)$ rapidamente após $\mathrm{o}$ 
consumo de colostro.

De forma semelhante, Silva et al. ${ }^{25}$, ao avaliarem oito cordeiros mestiços Santa Inês x Dorper em regime de mamada de colostro monitorada, verificaram baixos valores de proteína sérica total ao nascimento $(36,2 \mathrm{~g} / \mathrm{L})$, que apresentaram aumento significativo às seis horas $(75,5 \mathrm{~g} / \mathrm{L})$ e atingiram concentração máxima no período de $24-72$ horas de vida $(79,8$ $\mathrm{g} / \mathrm{L})$. Os valores de globulinas também foram mínimos antes do recebimento do colostro (aproximadamente 15,7 g/L), apresentando aumento significativo às seis horas $(47,7 \mathrm{~g} / \mathrm{L}) \mathrm{e}$ pico de seus valores às 24-72 horas de vida $(52,8 \mathrm{~g} / \mathrm{L})$. É importante ressaltar que a fração de gamaglobulinas foi a que apresentou variação mais expressiva entre o nascimento e 24-72 horas de vida (3,2 $\mathrm{g} / \mathrm{L}$ para 33,9 $\mathrm{g} / \mathrm{L})$.

Essa dinâmica é frequente entre os ruminantes, uma vez que durante a vida intrauterina os mesmos não recebem proteínas e anticorpos maternos em quantidades suficientes por via transplacentária. Assim, logo após o nascimento, as concentrações de globulinas totais e, consequentemente, de proteínas totais são mínimas ${ }^{5,7,8,29}$. No entanto, à medida que se oportuniza a absorção de imunoglobulinas maternas, pelo consumo de colostro, ambas as concentrações se elevam significativamente ${ }^{1,7,8}$. Isso ocorre pela alta correlação entre globulinas séricas e globulinas colostrais, especialmente imunoglobulinas $\mathrm{G}$ ( $\operatorname{IgG})$, inexistindo aumento dos teores séricos proteicos quando são fornecidos leite ou substitutos de colostro para ruminantes neonatos ${ }^{30,31}$. Além disso, estudos demonstram que os teores séricos proteicos relacionam-se diretamente à quantidade e ao tempo de fornecimento de colostro ${ }^{32}$ e podem variar em função da qualidade da dieta consumida pelas ovelhas em lactação ${ }^{33}$.

Os cordeiros deste estudo apresentaram alternância simultânea entre o predomínio das frações albumina e de globulinas totais, antes e após a ingestão de colostro, constatando-se decréscimo $(P<0,05)$ da concentração de albumina após 72 horas de vida. Em contraste, os cordeiros avaliados por Silva et al. ${ }^{25}$ apresentaram aumento dessa fração de $20,5 \mathrm{~g} / \mathrm{L}$ para $27,1 \mathrm{~g} / \mathrm{L}$ entre o nascimento e as primeiras 24-72 horas de vida, o que foi justificado como decorrente do aumento da ingestão de compostos nitrogenados na dieta. Feitosa et al. ${ }^{34}$ também observaram predominância da albumina no soro, em bezerros, a partir de 24 horas após a ingestão de colostro, com aumento significativo a partir das 48 horas e, em cabritos, após os 15 dias.

Neste estudo, porém, admite-se que a variação observada relacionou-se não apenas ao substancial aporte de nutrientes e imunoglobulinas suprido via colostro, que pode alterar a razão albumina:globulina, mas também ao desenvolvimento inicial dos processos metabólicos hepáticos para síntese proteica (menos ativos que os processos de catabolismo), que são otimizados após o suprimento de colostro, amadurecendo ao longo das primeiras semanas de vida ${ }^{31}$. Dessa maneira, as oscilações nas concentrações de albumina parecem ter sido influenciadas, prioritariamente, pelo estado hipofuncional do fígado, órgão que detém exclusividade sobre sua síntese, resultando em lento turnover de albumina durante o período neonatal.

As concentrações pós-colostrais de bilirrubina total foram aproximadamente duas vezes mais elevadas $(P<0,001)$ do que as verificadas no momento pré-colostro. Essa variação, assim como se relata em bezerros e/ou em humanos neonatos, poderia ser ocasionada pelos seguintes fatores: maior metabolização de hemoglobina no sistema fagocítico mononuclear do fígado e do baço, devido à extensa destruição dos eritrócitos fetais ${ }^{32}$; aumento da taxa de reabsorção intestinal de bilirrubina indireta, como resquício da vida fetal ${ }^{1}$; menor aporte de ligandinas, proteínas auxiliares no carreamento da bilirrubina indireta ao retículo endoplasmático liso dos hepatócitos, onde se efetuam os processos de conjugação ${ }^{35}$; ou pela deficiência transitória de uridina-difosfatoglucuronosiltransferase, enzima responsável pela formação de monoglicuronato ou diglucuronato de bilirrubina, formas de bilirrubina conjugada ou direta ${ }^{36}$.

No entanto, como houve aumento concomitante apenas entre bilirrubina total $\mathrm{e}$ bilirrubina direta $(P<0,001)$, sem variações significativas nos teores de bilirrubina indireta $(P>0,05)$, a provável causa para esse comportamento seria a ocorrência de uma hiperbilirrubinemia fisiológica consequente à 
adaptação morfofuncional hepática à vida extrauterina. Nessa condição, o neonato apresentaria, além da maior predisposição para produção de bilirrubina, uma limitada habilidade para excreção da mesma, levando à temporária elevação sérica de bilirrubina direta ao invés da indireta $^{36}$.

Assim como em cabritos ${ }^{37}$ e em bezerros de leite ${ }^{38,39}$, os teores glicêmicos dos cordeiros foram relativamente baixos no momento précolostro, sugerindo a ocorrência fisiológica de hipoglicemia nos ruminantes ao nascer. Segundo Daniels et al. $^{40}$, isso é possível em cordeiros recém-nascidos, uma vez que a frutose consolida-se como fonte predominante de energia, sobrepujando a glicose, durante as primeiras 24 horas de vida. Essa alteração decorreria de limitações na digestão de lactose e absorção de glicose, associadas às pequenas reservas de glicogênio ou hipofunção do mecanismo enzimático para glicogenólise ao nascimento. No entanto, logo nas primeiras horas de vida deve ocorrer aumento da glicemia, devido à intensificação da utilização de glicogênio em resposta ao aumento da atividade eferente do sistema nervoso simpático, que ocorre mesmo na ausência da oferta de nutrientes ${ }^{1}$. Kurz e Willett ${ }^{1}$ observaram que, em bezerros neonatos, os valores glicêmicos permanecem em oscilação até a $12^{\mathrm{a}}$ hora de vida, refletindo o período de instabilidade fisiológica, até que o pâncreas e o fígado tornem-se completamente funcionais.

Além desses fatores, o aumento póscolostral da glicemia $(P<0,001)$ observado neste estudo estaria vinculado principalmente à amamentação, pois o consumo de nutrientes via colostro interfere diretamente sobre a absorção e o metabolismo de carboidratos, determinando o aumento das concentrações de glicose em períodos de pós-alimentação nos ruminantes neonatos ${ }^{41}$.

Por sua vez, foi observado aumento significativo $(P<0,001)$ nas concentrações de triglicerídeos e de colesterol total entre os momentos avaliados. De forma similar, Bennis et al. $^{42}$ também verificaram que, em cabritos recém-nascidos, as concentrações de triglicerídeos e de colesterol total são inferiores, próximas às relatadas em caprinos adultos, enquanto que, após a ingestão de colostro, tais parâmetros aumentam significativamente. Infere-se que as menores concentrações de colesterol e de triglicerídeos averiguadas no momento pré-colostro decorram de baixa produção endógena de ácidos graxos durante a vida fetal, e que a subsequente elevação póscolostral sofra ação direta do aporte de nutrientes provenientes da amamentação ${ }^{43}$.

Noble $^{43}$ confirma que cordeiros que consomem quantidades adequadas de colostro apresentam marcada hipertrigliceridemia conjunta ao aumento das concentrações de colesterol, ainda que em menor extensão, durante as primeiras 24 horas de vida, ao passo que esta variação não é apresentada por cordeiros submetidos ao fornecimento de dieta com baixos teores de gordura. O aumento da trigliceridemia nos cordeiros poderia ser ainda justificado pela relação existente entre as concentrações de triglicerídeos e de ácidos graxos livres na circulação, visto que, assim como em cabritos recém-nascidos, a formação de novas moléculas de triglicerídeos durante as primeiras 72 horas de vida reflete o processo de re-esterificação dos ácidos graxos livres nos hepatócitos ${ }^{37}$.

As concentrações séricas de creatinina dos cordeiros no momento pré-colostro foram aproximadamente quatro vezes maiores $(P<0,001)$ que as concentrações pós-colostrais. Da mesma maneira, as concentrações de creatinina em bezerros neonatos sofrem queda brusca do nascimento ao fim da primeira semana de vida, em resposta à adaptação às alterações fisiológicas para manutenção da homeostase ${ }^{1,2,44}$.

Esse resultado poderia estar relacionado aos relatados por Lupke et al. ${ }^{45}$, que sugeriram que concentrações mais elevadas, em bezerros, ao nascimento seriam resultantes de acúmulo de creatinina ingerida do fluido alantóico durante a gestação. Ainda, semelhante ao que se relata em coelhos e em seres humanos, poderia ser ocasionado pela baixa maturidade do sistema urinário na fase neonatal, que possibilitaria a reabsorção de creatinina através dos túbulos renais, e sua presença em maiores níveis na circulação $^{46}$. Entretanto, uma vez que após a ruptura do cordão umbilical os rins assumem a função excretória e de controle do balanço hidroeletrolítico, sua causa mais provável seria a elevação gradativa do fluxo sanguíneo renal 
associada ao aperfeiçoamento do clearance renal e ao aumento da taxa de filtração glomerular durante a primeira semana de vida ${ }^{1}$ 32,47 . Isso desencadearia a diminuição do aporte de creatinina sérica do neonato ao longo dos dias, tal como observado neste estudo.

A dinâmica da ureia nos cordeiros demonstrou perfil similar ao verificado em cordeiros Saidi $^{48}$, com elevação de suas concentrações $(P<0,01)$ nas primeiras horas após a ingestão de colostro. $\mathrm{Na}$ ausência de disfunções renais ou hepáticas, essa variação é determinada pelo consumo, produção e degradação de proteína da $\operatorname{dieta}^{31}$. Portanto, as concentrações de ureia dos cordeiros foram possivelmente modificadas em função do consumo e degradação das proteínas colostrais. Além disso, é importante ressaltar que, durante a fase neonatal, as concentrações de ureia podem ser ainda influenciadas fortemente pelo fator etário, à medida que a função renal atinge à maturidade ${ }^{49}$.

A enzima AST localiza-se principalmente no citoplasma ou mitocôndria dos hepatócitos e/ou das fibras musculares esqueléticas e cardíacas $^{50,}{ }^{51}$. O aumento $(P<0,001)$ de quase três vezes dos valores de AST observado nos cordeiros no momento póscolostro, assim como nos demais ruminantes hígidos durante a fase pós-natal, resultaria: de presença de AST na composição do colostro e de sua absorção ${ }^{52}$; de injúria muscular causada durante o parto ou pelo aumento da atividade física dos animais ${ }^{53}$; ou ainda, do desenvolvimento das funções fisiológicas com o progresso da idade ${ }^{19,49,54}$.

Tollersrud e Baustad $^{55}$, entretanto, constataram elevação semelhante entre as concentrações séricas de AST em cordeiros privados ou não da ingestão de colostro, refutando a hipótese de que o colostro contenha níveis de AST em quantidade suficiente para promover detecção de maior atividade da mesma na circulação. Em concordância, outros pesquisadores $^{6,}{ }^{56-58}$ observaram elevação das concentrações sanguíneas de AST, independente ao tempo de liberação à primeira mamada, e mesmo sob pequena atividade da enzima no colostro. Consideraram, portanto, que a correlação obtida entre $\operatorname{IgG}$ e o aumento dos níveis de AST seria, na verdade, decorrente de maior produção endógena desta enzima pela borda em escova dos enterócitos, e isso em resposta à ingestão de colostro.

Por sua vez, o aumento da atividade sérica de AST, se derivado de lesões musculares durante o parto ou pela intensificação da atividade física, deveria ser acompanhado por aumento da atividade de CK, enzima de eleição na indicação de danos musculares, como validado nos estudos de Benesi et al. ${ }^{35} \mathrm{e}$ de Britti et al. ${ }^{6}$. Porém, uma vez que as concentrações de CK mantiveram-se estáveis $(P>0,05)$ desde o nascimento até as 72 horas de vida dos cordeiros, os resultados do presente estudo possivelmente decorrem do processo de adaptação morfofuncional do fígado com o desenvolvimento etário ${ }^{2}$.

$$
\text { O aumento } \quad(P<0,001), \quad \text { de }
$$

aproximadamente 16 vezes, da atividade sérica de GGT observado nos cordeiros no momento pós-colostro apresentou relação direta com o consumo de colostro, o qual possui elevadas concentrações desta enzima em sua constituição ${ }^{59}$. Em ruminantes, a GGT pode ser encontrada no epitélio dos ductos das glândulas mamárias, onde se envolve no processo de síntese do colostro ${ }^{9,59,60}$. Nos cordeiros, a GGT é absorvida pelo mesmo mecanismo da IgG. Dessa forma, a absorção dessas macromoléculas via colostro, com a diminuição da permeabilidade através do epitélio do intestino delgado e com o início de seus processos catabólicos, limita-se às primeiras $24-48$ horas após o nascimento ${ }^{6}$.

Conforme Maden et al. ${ }^{29}$, picos nas concentrações de GGT podem ser observados logo após a primeira mamada de colostro, os quais são verificados especialmente durante os primeiros três dias de vida extra-uterina. Assim, devido à elevada concentração e consistente correlação entre GGT e $\operatorname{IgG}^{9}$, sua atividade enzimática, tanto no fluido colostral como no soro de cordeiros, tem sido aceita como índice indireto de transferência de imunidade passiva ${ }^{24}$. Além disso, é importante ressaltar que, durante o período neonatal, a atividade da GGT não deve ser utilizada como marcadora de doença hepática, ainda que em animais de idade mais avançada essa seja destacada como sua principal função ${ }^{60}$.

De fato, a avaliação da função hepática 
nos cordeiros recém-nascidos deve ser realizada com extrema cautela, visto que as variações das atividades de AST e GGT, em conjunto àquelas verificadas entre os parâmetros proteicos e energéticos, sugerem condição de intensas modificações no fígado durante os primeiros dias pós-natais.

\section{CONCLUSÕES}

A dinâmica dos parâmetros bioquímicos em cordeiros neonatos sadios é modificada pela ingestão de colostro e pela adaptação dos processos fisiológicos do animal à vida extrauterina.

À exceção da creatinina, da bilirrubina indireta e da enzima $\mathrm{CK}$, todos os demais parâmetros avaliados neste estudo parecem servir como indicadores indiretos da ingestão de colostro pelos cordeiros.

Os valores de proteínas totais e de suas frações (globulinas e albumina), de bilirrubinas, de indicadores do metabolismo energético (glicose, triglicerídeos e colesterol), dos marcadores da função renal (ureia e creatinina) e das enzimas AST e GGT variam marcadamente durante as primeiras horas de vida. Assim, é altamente recomendável o uso de valores de referência específicos para este período, visando evitar equívocos na interpretação dos exames laboratoriais de cordeiros neonatos.

Os valores obtidos neste estudo, ainda que provenham de uma população amostral relativamente pequena e homogênea, podem ser utilizados como valores de referência preliminares para a fase neonatal. Futuramente, em conjunto aos dados de outros estudos, poderão ser extrapolados para a população brasileira de cordeiros neonatos.

\section{REFERÊNCIAS}

1. Kurz M, Willett L. Carbohydrate, enzyme, and haematology dynamics in newborn calves. Journal of Dairy Science. 1991;74:2109-2118.

2. Piccione G, Casella S, Pennisi P, Giannetto C, Costa A, Caola G. Monitoring of physiological and blood parameters during perinatal and neonatal period in calves. Arquivo Brasileiro de Medicina Veterinária e Zootecnia. 2010;62(1):1-12.

3. Keller HL, Gherman LI, Kosa RE, Borger DC, Weiss
WP, Willett LB. Kinetics of plasma fructose and glucose when lactose and fructose are used as energy supplements for neonatal calves. Journal of Animal Science. 1998;76(8):2197-2204.

4. Dwyer CM. The welfare of the neonatal lamb. Small Ruminant Research. 2008;76(1):31-41.

5. Sawyer M, Willadsen CH, Osburn BI, McGuire TC. Passive transfer of colostral immunoglobulins from ewe to lamb and its influence on neonatal lamb mortality. Journal of American Veterinary Medical Association. 1977;171(12):1255-1259.

6. Britti D, Massimini G, Peli A, Luciani A, Boari A. Evaluation of serum enzyme activities as predictors of passive transfer status in lamb. Journal of American Veterinary Medical Association. 2005;226(6):951-955.

7. Silva SL, Fagliari JJ, Baroza PFJ, Cesco FTRS, Jorge RLN. Avaliação da imunidade passiva em caprinos recém-nascidos alimentados com colostro de cabras ou colostro de vacas. Ars Veterinaria. 2007;23(2):81-88. Portuguese.

8. Yanaka R, Camargo DG, Bovino F, Santos WA, Dócusse MR, Cavassano BS, et al. Período de absorção intestinal de macromoléculas em cabritos recém-nascidos após a ingestão de colostro bovino. Pesquisa Veterinária Brasileira. 2012;32(8):794-802. Portuguese.

9. Zarrilli A, Micera E, Lacarpia N, Lombardi P, Pero ME, Pelagalli A, et al. Evaluation of ewe colostrum quality by estimation of enzyme activity levels. Revue Médicine Vétérinaire. 2003;154(8-9):521-523.

10. Nowak R, Poindron P. From birth to colostrum: early steps leading to lamb survival. Reproduction Nutrition Development. 2006;46(4):431-446.

11. Hernández-Castellano LE, Almeida AM, Ventosa M, Coelho AV, Castro N, Argüello A. The effect of colostrum intake on blood plasma proteome profile in newborn lambs: low abundance proteins. BMC Veterinary Research. 2014;10(85):1-9.

12. Gardner DE. Values for certain blood and urine constituents of normal young lambs. New Zealand Veterinary Journal. 1973;21(4):70-73.

13. Rico AG, Braun JP, Bénard P. Blood reference values in the lamb $(\mathrm{Na}, \mathrm{K}, \mathrm{Ca}, \mathrm{P}, \mathrm{Mg}, \mathrm{Cu}, \mathrm{Zn}, \mathrm{Cl}$, urea, total proteins, creatinine, uric acid, alkaline phosphatase, aspartate amino transferase, cholesterol and hemoglobin). Annales de Recherches Vétérinaires.1976;7(3):241-252.

14. Mellor DJ, Pearson RA. Some changes in the composition of blood during the first 24 hours after birth in normal and growth retarded lambs. Annales de Recherches Vétérinaires. 1977;8(4):460-467.

15. Bickhardt $K$, Dudziak D, Ganter M, Henze $P$. [Investigations on dependence of hematologic and blood chemical parameters on the age of health lambs: a contribution to the definition of reference values in sheep]. Deutsche Tierarztliche Wochenschrift. 1999;106(10):445451. German. 
16. Stafford KJ, Kenyon PR, Morris ST, West DM. The physical state and metabolic status of lambs of different birth rank soon after birth. Livestock Science. 2007;111:10-15.

17. Bórnez R, Linares MB, Vergara H. Haematological, hormonal and biochemical blood parameters in lamb: effect of age and blood sampling time. Livestock Science. 2009;121:200-206.

18. Lepherd ML, Canfield PJ, Hunt GB, Bosward KL. Haematological, biochemical and selected acute phase protein reference intervals for weaned female Merino lambs. Australian Veterinary Journal. 2009;87(1-2):5-11.

19. Meira Jr EBS, Rizzo H, Benesi FJ, Gregory L. Influência dos fatores sexuais e etários sobre a proteína total, fração albumina e atividade sérica de aspartatoaminotransferase e gama-glutamiltransferase de ovinos da raça Santa Inês. Brazilian Journal of Veterinary Research and Animal Science. 2009;46(6):448-454. Portuguese.

20. Madureira KM, Gomes V, Barcelos B, Zani BH, Shecaira CL, Baccili CC, et al. Parâmetros hematológicos e bioquímicos de ovinos da raça Dorper. Semina: Ciências Agrárias. 2013;34(2):811-816. Portuguese.

21. Flaiban KKMC, Costa MC, Balarin MRS, Ribeiro ELA, Mori RM, Lisbôa JAN. Transferência de imunidade passiva em cordeiros cujas mães sofreram restrição protéica no terço final de gestação. Archives of Veterinary Science. 2007;12(Suppl):S187-188. Portuguese.

22. Flaiban KKMC, Balarin MRS, Ribeiro ELA, Castro FAB, Mori RM, Lisbôa JAN. Transferência de imunidade passiva em cordeiros cujas mães receberam dietas com diferentes níveis de energia ou proteína no terço final de gestação. Ciência Animal Brasileira. 2009;1(Suppl):S181185. Portuguese.

23. Silva DFM, Costa JN, Araújo AL, Carvalho S, Peixoto APC, Alves LO, et al. Falha da transferência da imunidade passiva em cordeiros mestiços (Santa Inês $x$ Dorper): efeito no proteinograma e taxa de mortalidade do nascimento até o desmame. Ciência Animal Brasileira. 2009;1(Suppl):S158-163. Portuguese.

24. Féres FC, Lombardi AL, Barbosa TS, Mendes LCN, Peiró JR, Cadioli FA, et al. Avaliação da transferência de imunidade passiva em cordeiros com até 30 dias de idade. Brazilian Journal of Veterinary Research and Animal Science. 2010;47(3):231-236. Portuguese.

25. Silva DFM, Costa JN, Araújo AL, Costa Neto AO, Almeida MAO, Carvalho VS. Proteinograma sérico de cordeiros mestiços (Santa Inês x Dorper) do nascimento até o desmame: efeito do desenvolvimento etário e do monitoramento da ingestão de colostro. Ciência Animal Brasileira. 2010;11(4):794-805. Portuguese.

26. Turquino CF, Flaiban KKMC, Lisbôa JAN. Transferência de imunidade passiva em cordeiros de corte manejados extensivamente sob condição de clima tropical. Pesquisa Veterinária Brasileira. 2011;31(3):199-205. Portuguese.
27. Costa JN, Silva DFM, Lima CCV, Souza TS, Araújo AL, Costa Neto AO, et al. Falha da transferência de imunidade passiva em cordeiros mestiços (Santa Inês $\mathrm{x}$ Dorper) e estudo do proteinograma do nascimento até o desmame. Brazilian Journal of Veterinary Research and Animal Science. 2013;50(2):114-120. Portuguese.

28. R Development Core Team. The R Project for Statistical Computing [Free Software Programming Language]. Version 2.10.1. Auckland (NZ): R Project; 2009. Available from: http://www.r-project.org

29. Maden M, Altunok V, Birdane FMB, Aslan V, Nizamlioglu M. Blood and colostrums/milk serum gamma-glutamyltransferase activity as a predictor of passive transfer status in lambs. Journal of Veterinary Medicine - Series B. 2003;50(3):128-137.

30. Chen JC, Chang CJ, Peh HC, Chen SY. Serum protein levels and neonatal growth rate of Nubian goat kids in Taiwan area. Small Ruminant Research. 1999;32(2):153160.

31. Blum JW, Hammon H. Colostrum effects on the gastrointestinal tract, and on nutritional, endocrine and metabolic parameters in neonatal calves. Livestock Production Science. 2000;66(2):151-159.

32. Mohri M, Sharifi K, Eidi S. Hematology and serum biochemistry of Holstein dairy calves: age related changes and comparison with blood composition in adults. Research in Veterinary Science. 2007;83:30-39.

33. Hashemi M, Zamiri MJ, Safdarian M. Effects of nutritional level during late pregnancy on colostral production and blood immunoglobulin levels in Karakul ewes and their lambs. Small Ruminant Research. 2008;75(2):204-209.

34. Feitosa FLF, Mendes LCN, Peiró JR, Ciarlini PC, Marques FJ, Takada L, et al. Comparação do proteinograma e da atividade da gamaglutamiltransferase no soro sangüíneo de bezerros e de cabritos após ingestão de colostro. Ars Veterinaria. 2006;22(1):16-21. Portuguese.

35. Benesi FJ, Leal MLR, Lisboa JAN, Coelho CS, Mirandola RMS. Parâmetros bioquímicos para avaliação da função hepática em bezerras sadias, da raça Holandesa, no primeiro mês de vida. Ciência Rural. 2003;33(2):311317. Portuguese.

36. Dennery PA, Seidman DS, Stevenson DK. Neonatal hyperbilirubinemia. The New England Journal of Medicine. 2001;344(8):581-590.

37. Gregory L, Bardese CB, Birgel Jr EH, Meira Jr EBS, Piva FM, Hasegawa MY. Lipidograma e glicemia de caprinos da raça Saanen, durante os primeiros dias de vida. Ars Veterinaria. 2009;25(3):109-115. Portuguese.

38. Shannon AD, Lascelles AK. Changes in the concentration of lipids and some other constituents in the blood plasma of calves from birth to 6 months of age. Australian Journal of Biological Sciences. 1966;19(5):831-839. 
39. Kaneto FM, Coelho CS, Leal MLR, Lisbôa JAN, Benesi FJ. Glicemia e "anion-gap" em bezerras sadias da raça Holandesa no primeiro mês de vida. Ars Veterinaria. 2004;20(3):291-298. Portuguese.

40. Daniels LB, Perkins JL, Krieder D, Tugwell D, Carpenter D. Blood glucose and fructose in the newborn ruminant. Journal of Dairy Science. 1974;57(10):11961200 .

41. Kurz MM, Willett LB. The clearance of carbon-14fructose, carbon-14-glucose and carbon-14-sorbitol by calves at birth and 7 days of age. Journal of Dairy Science. 1992;75(1):236-246.

42. Bennis A, de La Farge F, Bézille P, Valdiguié P, Rico AG, Braun JP. Effects of age of newborn and delivery by female goats on plasma lipids and lipoproteins. Small Ruminant Research. 1992;9:243-253.

43. Noble RC. Lipid metabolism in the neonatal ruminant. Progress in Lipid Research. 1979;18(4):179-208.

44. Benesi FJ, Coelho CS, Leal MLR, Mirandola RMS, Lisbôa JAN. Parâmetros bioquímicos para avaliação da função renal e do equilíbrio hidroeletrolítico em bezerras sadias, da raça Holandesa, no primeiro mês de vida. Brazilian Journal of Veterinary Research and Animal Science. 2005;42(4):291-298. Portuguese.

45. Lupke H, Mulling M, Sohn E. [Investigations of maternofetal correlations of cattle. 2. The content of total nitrogen, urea, uric acid and creatinine of the amniotic and allantoic fluid]. Berliner und Munchener Tierarztliche Wochenschrift. 1967;80:449-450. German.

46. Matos P, Duarte-Silva M, Drukker A, Guignard JP. Creatinine reabsorption by the newborn rabbit kidney. Pediatric Research. 1998;44:639-641.

47. Aperia A, Broberger O, Herin P, Joelsson I. Renal hemodynamics in the perinatal period. A study in lambs. Acta Physiologica Scandinavica. 1977;99(3):99-261.

48. Teleb DF, Saifelnasr EOH, El-Sayed EH. Factors affecting performance and survivability of Saidi lambs from lambing to weaning. Egyptian Journal of Sheep \& Goat Sciences. 2009;4(1):55-74.

49. Gasparelli EF, Camargo DG, Yanaka R, Féres FC, Vieira RFC, Perri SHV, et al. Influência do tipo de parto nos valores das enzimas hepáticas e de uréia e creatinina de bezerros Nelore oriundos de fertilização in vitro (FIV) e in vivo (FV) ao nascimento e às 24 horas de vida. Veterinária e Zootecnia. 2008;15(2):360-389. Portuguese.
50. Keller P. Enzyme activities in the dog: tissue analysis, plasma values, and intracellular distribution. American Journal Veterinary Research. 1981;42:575-582.

51. Boyd JW. The mechanisms relating to increases in plasma enzymes and isoenzymes in diseases of animals. Veterinary Clinical Pathology. 1983;12:9-24.

52. Maderova V, Neuman V, Kozumplik F. [Development of serum transaminase activity in very young calves]. Sborn Vyz SK Zemeldelska Brno. 1963;11:187-188. Czech.

53. Boyd JW. Serum enzyme changes in newborn calves fed colostrum. Veterinary Clinical Pathology. 1989;18(2):47-51.

54. Delfino JL, Barbosa VM, Gondim CC, Oliveira PM, Nasciutti NR, Oliveira RSBR, et al. Perfil bioquímico sérico de bezerros Senepol nos primeiros 120 dias de idade. Semina: Ciências Agrárias. 2014;35(3):1341-1350. Portuguese.

55. Tollersrud S, Baustad B. Serum enzyme activity of newborn calves, pigs and lambs. Acta Veterinaria Scandinavica. 1970;11(4):525-535.

56. Pauli JV. Colostral transfer of gamma glutamyl transferase in lambs. New Zealand Veterinary Journal. 1983;31(9):150-151.

57. Zanker IA, Hammon HM, Blum JW. Activities of $\gamma$ glutamyltransferase, alkaline phosphatase and aspartateaminotransferase in colostrum, milk and blood plasma of calves fed first colostrum at $0-2,6-7,12-13$ and $24-25 \mathrm{~h}$ after birth. Journal of Veterinary Medicine. A Physiology, Pathology, Clinical Medicine. 2001;48(3):179-185.

58. Feitosa FLF, Mendes LCN, Peiró JR, Cadioli FA, Yanaka R, Bovino F, et al. Influência da faixa etária nos valores de enzimas hepáticas e de uréia e creatinina em bezerros holandeses do nascimento até os 365 dias de vida. Ciência Veterinária nos Trópicos. 2007;10(2-3):5461. Portuguese.

59. Braun JP, Bernard P, Burgat V, Rico AG. Gamma glutamyl transferase in domestic animals. Veterinary Research Communications. 1983;6(2):77-90.

60. Russell KE, Roussel AJ. Evaluation of the ruminant serum chemistry profile. Veterinary Clinics Food Animal Practice. 2007;23(3):403-426. 